\title{
Numerical comparison between single layer woven flexible pipe and reinforced thermoplastic pipe
}

\author{
A. Akram ${ }^{1}$, Z. Mustaffa ${ }^{1}$, T. M. B. Albarody ${ }^{2}$ and J. E. Edmund ${ }^{1}$ \\ ${ }^{1}$ Civil and Environmental Engineering Department, Universiti Teknologi PETRONAS \\ (UTP), 32610 Bandar Seri Iskandar, Perak Darul Ridzuan, Malaysia, \\ ${ }^{2}$ Mechanical Engineering Department, Universiti Teknologi PETRONAS (UTP), 32610 \\ Bandar Seri Iskandar, Perak Darul Ridzuan, Malaysia, \\ Phone: +6053688000; Fax: +6053654088 \\ *Email: aliakram92@gmail.com
}

\begin{abstract}
The weight of a conventional flexible pipe and corrosion poses a major challenge for pipelines at significant water depths, making composite material an ideal alternative for steel in the armor layers. A woven configuration was developed for the armour layer by utilising glass epoxy, namely the woven flexible pipe. However, the performance of the woven flexible pipe in deep water conditions are unknown, thus the need for a numerical analysis. In this paper, an initial comparison was conducted for the woven flexible pipe with a typical bonded flexible pipe called the thermoplastic reinforced pipe, where one layer of the woven flexible pipe is considered to show its performance. The results showed higher stress experienced by the woven flexible pipe as compared to the reinforced thermoplastic pipe, where the lowest difference was $50.8 \%$. It was also shown that the woven flexible pipe can withstand the $6 \mathrm{MPa}$ internal pressure at a thickness of 6 $\mathrm{mm}$ and above. The result is still inconclusive as an experiment test is required to validate the results. However, it serves as a good estimation of the expected result for future experimental test.
\end{abstract}

Keywords: Flexible pipeline; composite material; woven.

\section{INTRODUCTION}

Unbonded flexible pipe has been successfully used as a dynamic riser and static flowline for over 30 years. This performance is due to the configuration of the unbonded flexible pipe which consists of multiple layers, each with their own unique function $[1,2]$. However, as the amount of hydrocarbon from shallow water reservoir continue to dwindle, attention has been diverted to deep water and ultra-deep water for more supply. This poses a challenge in terms of the pipeline weight due to the metal armour layers [36]. Although this can be solved by using buoyancy modules [6], the deployment of buoyancy modules also leads to an increase in overall installation costs [7]. In addition to that, corrosion also becomes an issue due to the presence of water and corrosive gasses, such as carbon dioxide $\left(\mathrm{CO}_{2}\right)$ and hydrogen sulphide $\left(\mathrm{H}_{2} \mathrm{~S}\right)$, which can permeate through the internal sheath into the annulus area [8-12]. This condition is further aggravated in the event that the external sheath is breached or damaged, allowing seawater to mix with the gas to produce a corrosive environment $[2,9,13]$. Considering this matter, extensive research was made in replacing the steel armour layer with composite materials which 
were proven to be lighter and has more resistance towards corrosion $[6,7,14,15]$. In addition to that, a woven configuration was proposed, combining the hoop layer and tensile layers into a single layer. This design allows the hoop layer to contribute in resisting tensile forces and likewise, the tensile layer contributes in resisting hoop stresses due to the interlocking mechanism of the woven configuration. However, given the highpressure conditions of deep water environment, the woven configuration of thermosetting tapes is yet to be tested under high pressure loads, thus the need for a numerical analysis and experimental test for verification purposes.

The proposed non-metallic flexible pipe is a woven flexible pipe made from glass epoxy tapes woven in the hoop and axial direction, all of which are unbonded to allow movement of the tapes, thus increasing overall flexibility of the pipe. An experimental study would require a sophisticated equipment to weave the tapes according to the desired direction, much like the filament winding machine. The only difference is that the weaving tapes are all unbonded, which proves to be a great challenge in fabricating such a flexible pipe. Therefore, a numerical analysis was performed by using ANSYS for the woven flexible pipe and the results were compared with a typical bonded flexible pipe, called the thermoplastic reinforced pipe, to compare their performance. The objective is to study the performance of a single layer woven flexible pipe by using varying thickness. A typical unbonded flexible pipe consists of several layers, where each layer serves a specific function. The key layers as well as their function are shown in Figure 1 and Table 1. The performance of the sheath depends on the material used, which are usually high density polyethylene (HDPE), polyamide 11, and polyvinylidene fluoride (PVDF). Among these materials, PVDF polymers present the best chemical compatibility and highest continuous sustainable temperature of $130^{\circ} \mathrm{C}$ and above [16]. Other layers are also applied when needed, such as anti-wear tape between the layers, and aramid fibres which are wrapped around the armour layers to prevent birdcaging. However, in view of corrosion and weight issues, different materials are sought for replacement which are composite materials.
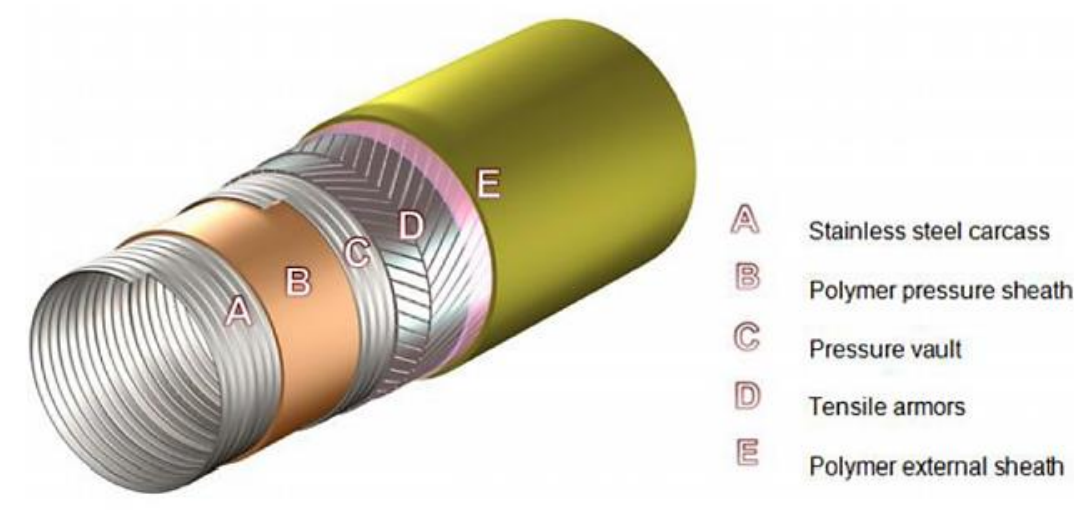

Figure 1. Typical flexible pipe construction with main layers [16].

Composite material is seen as an attractive alternative in the offshore industry due to its high strength to weight ratio. The properties are largely dependent on its components, namely the matrix and the reinforcement where the matrix discussed will be a thermosetting resin owing to its higher mechanical properties. In offshore applications, Gibson [17] simplified the selection criteria for resins into three, which are cost, flammability and mechanical properties. However, chemical resistance should also be 
considered due to the presence of corrosive substances. The matrix is selected from the most common thermoset used for structural purposes, that is polyester, vinyl ester, and epoxy. These materials are known for their good mechanical strength and chemical resistance. Among these resins, epoxy is the popular choice as it is regarded for its superior mechanical property and low degradation from water absorption [18].

Table 1. Key layers and functions of unbonded flexible pipe [10].

\begin{tabular}{|c|c|}
\hline Layer & Function \\
\hline Carcass & $\begin{array}{l}\text { Resists hydrostatic pressure and prevents collapse in the event of rapid } \\
\text { depressurisation. }\end{array}$ \\
\hline $\begin{array}{l}\text { Internal } \\
\text { sheath }\end{array}$ & Contains flow of product. \\
\hline $\begin{array}{l}\text { Pressure } \\
\text { armour }\end{array}$ & $\begin{array}{l}\text { Provides hoop resistance from internal pressure and external } \\
\text { hydrostatic pressure. }\end{array}$ \\
\hline $\begin{array}{l}\text { Tensile } \\
\text { armour }\end{array}$ & Provides tensile resistance \\
\hline $\begin{array}{l}\text { External } \\
\text { sheath }\end{array}$ & Protects internal parts from seawater and external impacts. \\
\hline
\end{tabular}

In terms of reinforcement, carbon fibre and glass fibre are usually chosen due to their strength. There are also cases where aramid fibre is used. Table 2 shows the generalisation of their mechanical property as well as cost and toxicity in fire [17], while Table 3 shows a comparison of fibre strength [19]. However, it is difficult to provide an accurate figure as it varies with different manufacturers, although it could still serve as a good reference. Thus, Table 4 provides a qualitative approach for comparison between polymers reinforced with the mentioned fibres [20]. Based on the material properties shown, the matrix and reinforcement fibre chosen are epoxy and glass fibres, respectively for the development of the woven flexible pipe. Although carbon fibre is superior in strength, it is believed that glass fibre also possesses a comparable strength. Since composite materials have excellent strength to weight ratio and high corrosion resistance, they are implemented in several flexible pipeline designs, which are called composite pipelines.

Table 2. Mechanical properties of thermosetting resins [17].

\begin{tabular}{lccc}
\hline Resin & $\begin{array}{c}\text { Mechanical } \\
\text { integrity }\end{array}$ & $\begin{array}{c}\text { Toxicity } \\
\text { in fire }\end{array}$ & Cost \\
\hline Polyester & $* * * * *$ & $*$ & $* * *$ \\
Vinyl ester & $* * * * * * *$ & $*$ & $* * * * * *$ \\
Epoxy & $* * * * * * * *$ & $*$ & $* * * * * * * *$ \\
Phenolic & $* * * * *$ & $* * * *$ & $* * * *$ \\
Mod Acrylic & $* * * *$ & $* * * * *$ & $* * * *$ \\
\hline
\end{tabular}

Table 3. Mechanical properties of reinforcement fibres [19].

\begin{tabular}{lccc}
\hline \multicolumn{1}{c}{ Fibre } & E glass & Aramid & Carbon \\
\hline Specific Gravity & 2.54 & 1.44 & 1.56 \\
Ultimate Tensile Strength (MPa) & 1550 & 1379 & 1600 \\
Young's Modulus (GPa) & 72.4 & 62.05 & 125 \\
\hline
\end{tabular}


Table 4. Qualitative comparison between reinforced polymers [20].

\begin{tabular}{lccc}
\hline \multicolumn{1}{c}{ Criterion } & Carbon & Aramid & E-Glass \\
\hline Tensile strength & Very good & Very good & Very good \\
Compressive strength & Very good & Inadequate & Good \\
Modulus of elasticity & Very good & Good & Adequate \\
Long term behaviour & Very good & Good & Adequate \\
Fatigue behaviour & Excellent & Good & Adequate \\
Bulk density & Good & Excellent & Adequate \\
Alkaline resistance & Very good & Good & Inadequate \\
Price & Adequate & Adequate & Very good \\
\hline
\end{tabular}

Table 5. Composite pipeline designs.

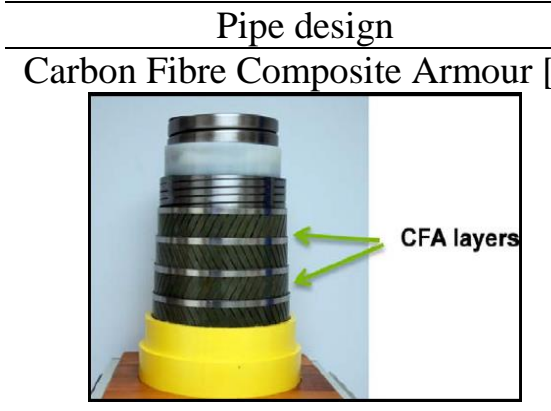

Flexible pipe using carbon fibre armour [6]

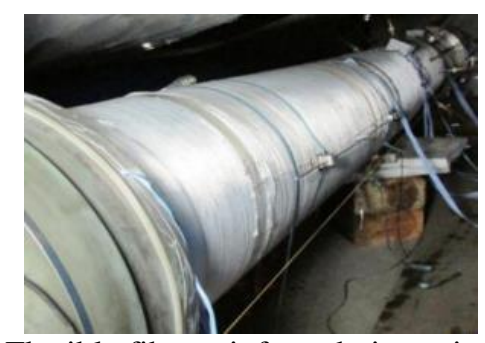

Flexible fibre reinforced pipe using carbon fibre [4]

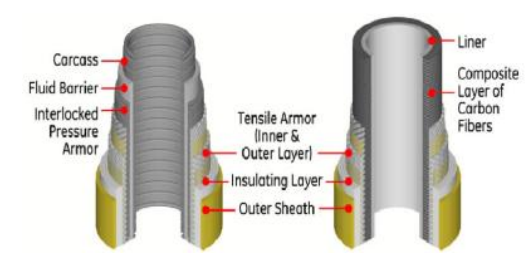

Unbonded flexible pipe employing glass epoxy [21]

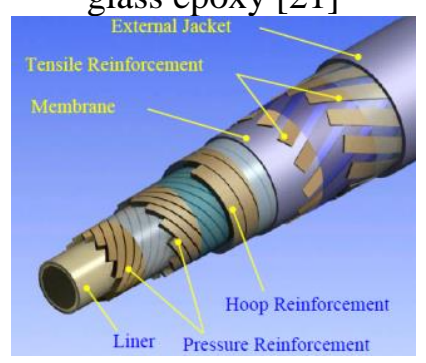

\section{Description}

- The steel armour layers are replaced with Carbon Fibre Armour layers (CFA) for weight reduction.

- The weight of an 11 inch CFA pipe was compared at a 2500-meter water depth.

- Weight comparison shows a reduction of $50-$ $55 \%$.

- A 20-inch flexible pipe where the steel armour layers are replaced with composite armours using carbon fibre (CFA).

- Weight comparison between the CFA pipe and the conventional 20 -inch flexible pipe shows a reduction of $30-34 \%$.
- The carcass and the hoop layer are combined into a single composite layer of carbon fibres. Weight comparison with a conventional flexible pipe shows a $30-35 \%$ weight reduction.

- The steel armour layers are replaced with glass epoxy composite

- Each layer of reinforcement is made of multi-start stacks of specially made pre-cured unidirectional composite tapes.

- Weight comparison with a conventional flexible pipe was mentioned to be roughly $50 \%$ reduction. 
The significant weight of the steel armour for deepwater installations and the threat of corrosion have prompted the development of several designs employing composite materials. A few designs of composite pipelines are detailed in Table 5. From Table 5, it can be deduced that the weight reduction gained from employing composite armours are roughly around 30 to $50 \%$. This reduction allows several advantages in pipeline installation. Arbey et al. [22] stated that the usage of lighter material for pipelines, specifically composite material, enables an increase of the maximum achievable water depth. This was calculated for different laying capacities, ranging from 400 tons to 1000 tons, as shown in Figure 2. However, care should be taken as too much reduction in weight could also cause complications, such as the stability of the pipe on the seabed. In such situation, additional weight, such as concrete covers are required. It is worth noting that, despite the advantages outlined, the issue in using composites are clearly identified in two areas which are the long term behaviour and the availability of trusted inspection methods [23]. The use of composites is further discouraged through the absence of a standard qualification process for composite pipelines. This matter however was studied by Kalman, Yu, \& Durr [24] which provided an extensive qualification process as well as a roadmap. Regarding the weight issues as well as the advantages of composite materials, a new design of flexible pipeline which adopts a woven configuration is developed. Details of the design can be found in the next section.

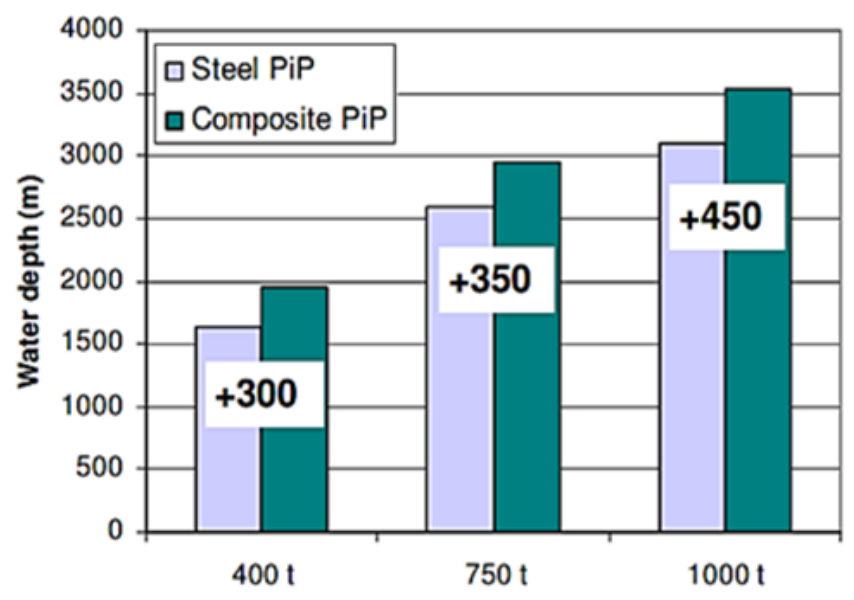

Figure 2. Pipe laying capacity [22].

\section{METHODS AND MATERIALS}

In this paper, a comparison stress analysis between the woven flexible pipe and a commercial flexible pipe, a reinforced thermoplastic pipe (RTP), is carried out by using ANSYS to study the performance of the woven flexible pipe. The flow of work involves the modelling of both pipes and the input of analysis parameters is shown in Figure 3. This RTP was selected owing to the fact that an existing stress analysis was conducted by [25] using the same model by Soluforce. Therefore, the loadings used for the numerical analysis will be identical to that of the existing study for verification purposes. The inner diameter will also be identical to the existing study as shown in Table 6 and Figure 4. The design details for the woven flexible pipe and RTP are explained later. 


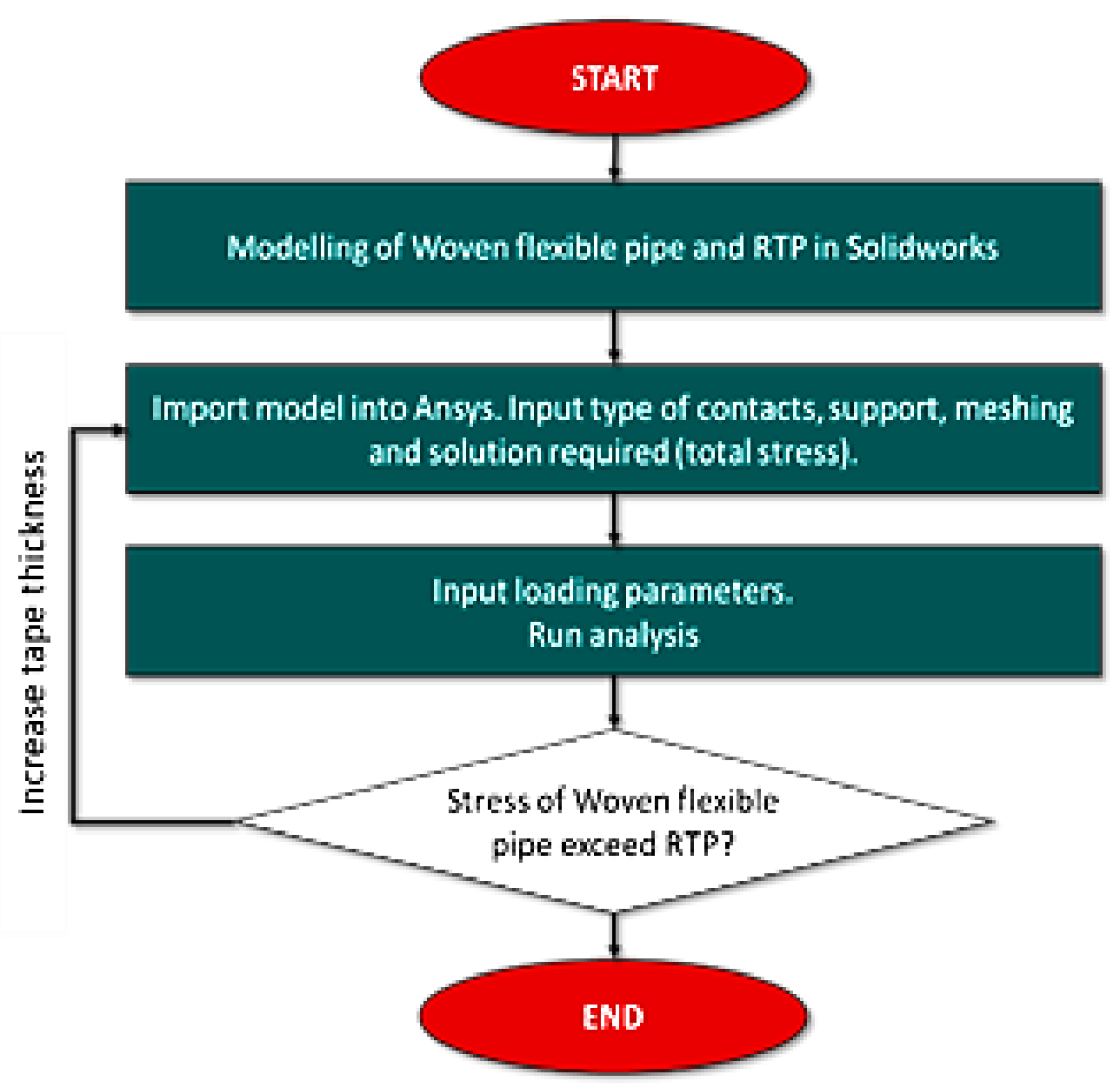

Figure 3. Flow of analysis.

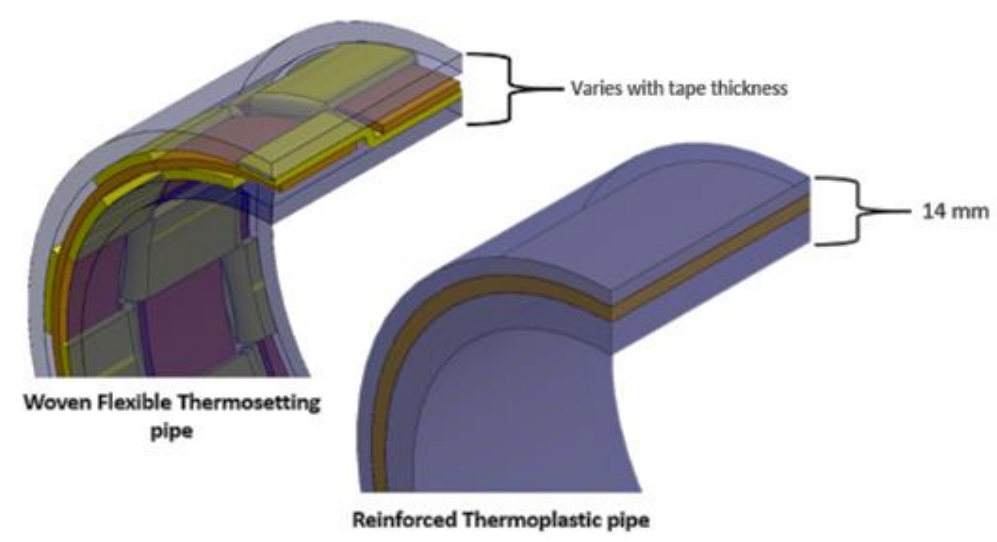

Figure 4. Wall thickness of woven flexible pipe and RTP.

Table 6. Thickness and diameter of pipes.

\begin{tabular}{ccc}
\hline Pipe & Thickness & Internal Diameter \\
\hline $\begin{array}{c}\text { Woven flexible pipe } \\
\text { RTP }\end{array}$ & $\begin{array}{c}14 \mathrm{~mm} \\
\text { Varies with tape thickness }\end{array}$ & $100 \mathrm{~mm}(4 \mathrm{inch})$ \\
\hline
\end{tabular}




\section{Woven Flexible Pipe Configuration}

The new composite flexible pipe is developed by using composite material, namely glass epoxy, which adopts a woven configuration to combine the armour layers into a single layer. The woven layer consists of unidirectional glass epoxy tape stacks which are in the axial direction and hoop direction. The near-hoop thermosetting tapes resist the internal and external pressure loadings while the near-axial thermosetting tapes resist the axial loads. If required, additional woven layers may be added to provide more strength for the pipe. However, given the conditions of the deepwater environment, the woven configuration of thermosetting tapes is yet to be tested under high pressure externally and internally. Thus, the need of a numerical analysis and experimental test for verification purposes. In this paper, only one layer of the woven flexible pipe will be analysed. The woven flexible pipe considered for analysis comprises three major elements, namely the hoop armour, the tensile armour and the polymer sheaths. Details of the design parameters are shown in Table 7 and Figure 5.

Table 7. Design parameters of the woven flexible pipe.

\begin{tabular}{lccc}
\hline \multicolumn{1}{c}{ Layers } & Width $(\mathrm{mm})$ & Thickness $(\mathrm{mm})$ & Material \\
\hline Longitudinal tape & 20 & $2-10$ & Glass epoxy \\
Hoop tape & 20 & $2-10$ & \\
Internal sheath & $100(\mathrm{ID})$ & 7 & Polyethylene \\
External sheath & - & 3.5 & \\
\hline
\end{tabular}

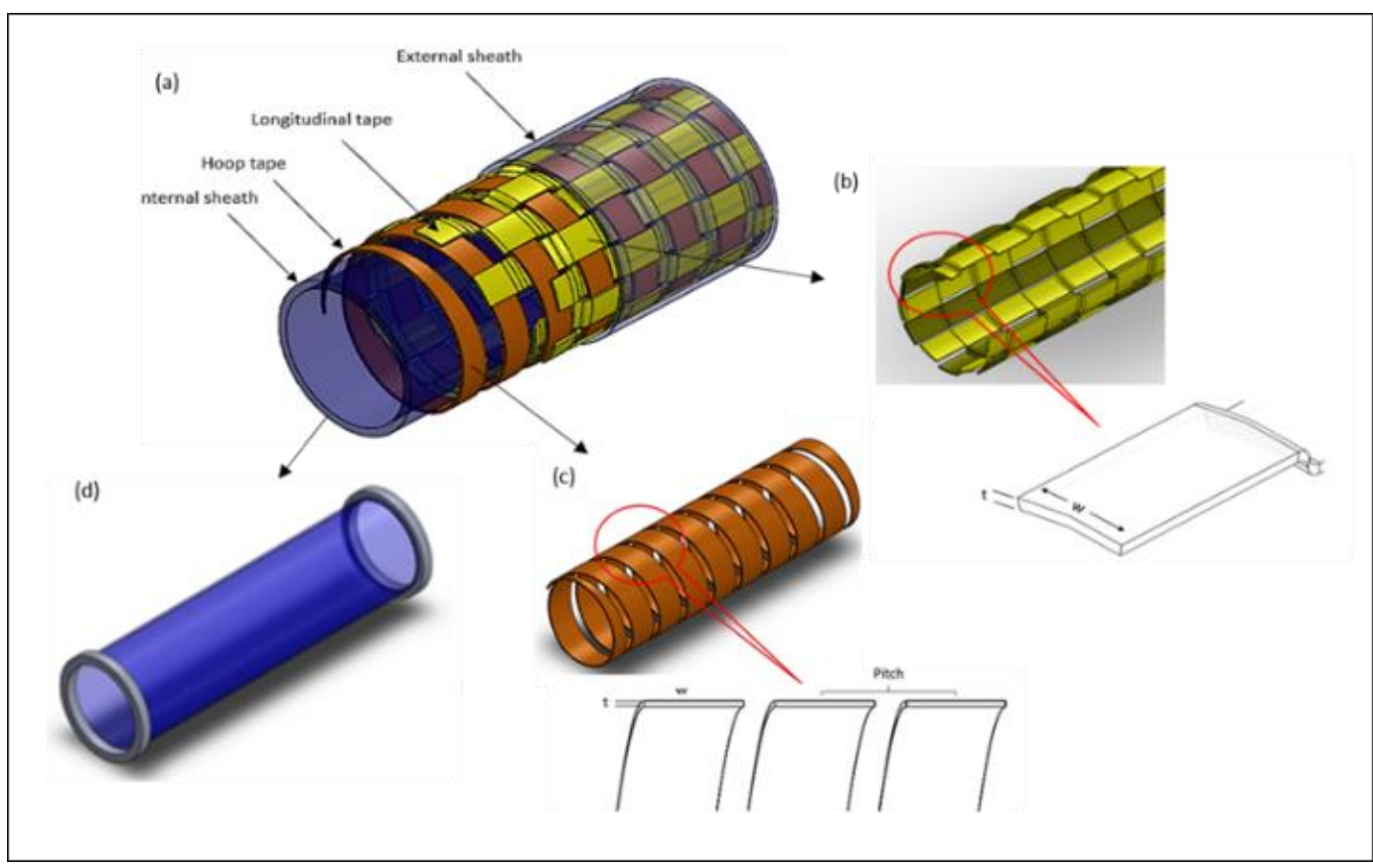

Figure 5: (a) Single layer woven flexible pipe (b) Longitudinal tape (c) Hoop tape (d) Polymer sheath

\section{Soluforce Reinforced Thermoplastic Pipe}

The RTP considered for comparison is a product by Soluforce, specifically the Soluforce M480 HPG. It is a three-layer bonded pipe consisting of a layer of aramid fibres sandwiched between two polymer layers. The design of the RTP is depicted in Figure 6. 
Similar to the typical flexible pipe, the inner and outer polymer layers act as a barrier to prevent seawater from reaching to the fibre layer. The synthetic fibre tape, which in this case is the aramid fibre, functions as a reinforcement layer for the RTP. The mechanical properties and design parameters used are referred to a stress-strain analysis carried out by Reutov [25] by using the same RTP to verify the results obtained. The mechanical properties and design parameters are shown in Table 8 . The loadings applied to both models are identical to the ones used by Reutov [25], which is an internal pressure of 6 $\mathrm{MPa}$, to verify the results. Normally, a comparison in performance is made by comparing the burst strength of pipes with reference to the ultimate tensile stress. However, since the ultimate tensile strength of the material used in the RTP was not given, it is difficult to predict the burst pressure of the RTP other than the maximum operating pressure provided by Soluforce. Therefore, the comparison was made with reference to the stress experience.

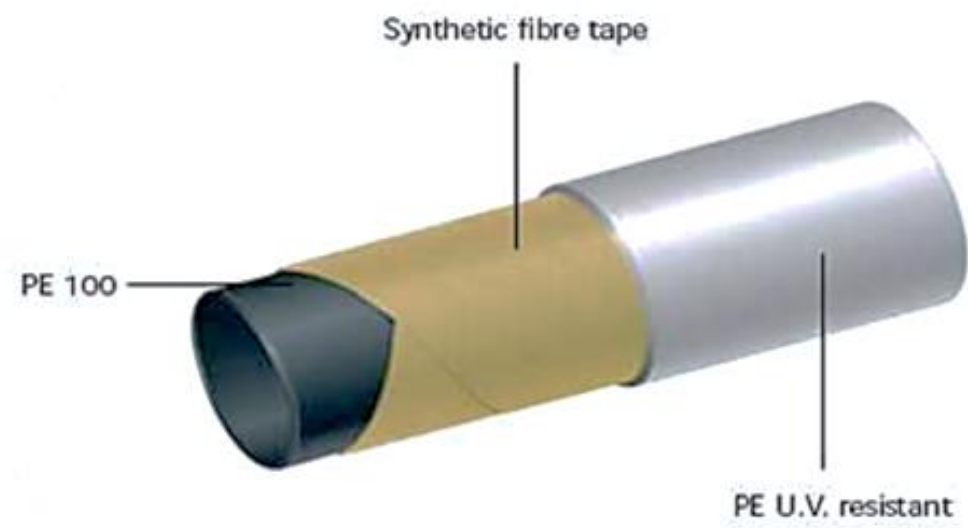

Figure 6. Reinforced Thermoplastic Pipe [25].

Table 8. Properties of Soluforce RTP [25].

\begin{tabular}{lccc}
\hline \multicolumn{1}{c}{ Pipe name } & \multicolumn{3}{c}{ Soluforce M480 HPG } \\
\hline Inner diameter, mm & \multicolumn{3}{c}{100} \\
Outer diameter, mm & Inner & Middle & Outer \\
Layer & 7 & 3.5 & 3.5 \\
Layer thickness, mm & PE 100 & Aramid Fibre & PE 100 \\
Layer material & 1300 & 10000 & 1300 \\
Young's modulus MPa & 0.43 & 0.3 & 0.43 \\
Poisson Ratio & 954 & 1440 & 954 \\
Density g/m & 0.38 & 0.04 & 0.38 \\
Thermal Conductivity coefficient, W/(m.K) & 1900 & 1420 & 1900 \\
Specific thermal capacity, $/(\mathrm{kg} . \mathrm{K})$ & $1.3(10)^{-4}$ & $4(10)^{-6}$ & $1.3(10)^{-4}$ \\
\hline Linear expansion coefficient, $\mathrm{K}^{-1}$ & \multicolumn{3}{c}{} \\
\hline
\end{tabular}

\section{RESULTS AND DISCUSSION}

Based on the parameters mentioned, the following results, as shown in Table 9, are obtained. From the results, at $6 \mathrm{MPa}$, the woven flexible pipe is able to withstand the load 
when the tape thickness is more than $6 \mathrm{~mm}$. This is determined based on the ultimate tensile strength of glass epoxy obtained from tensile tests, which is at $266 \mathrm{MPa}$. However, under the same pressure loading, the RTP experiences stress at approximately half of the RTP by using tape thickness of $10 \mathrm{~mm}$. Although the ultimate material strength of the RTP is not mentioned, it is stated by SoluForce that the Soluforce RTP is able to withstand pressure of up to 113 bar. Therefore, it is assumed that at $6 \mathrm{MPa}$, the RTP is experiencing $53 \%$ of the maximum stress.

Table 9. Stress analysis result.

\begin{tabular}{ccccccc}
\hline Tape thickness (mm) & 2 & 4 & 6 & 8 & 10 & RTP \\
Maximum stress (MPa) & 419.2 & 309.6 & 265.3 & 213.6 & 132.3 & 65.09 \\
\hline
\end{tabular}

$*$ Note that the table is the result of the analysis of one layer as shown in figure 5 .

In addition to that, it can be seen based on the stress experienced by the model, the RTP performs better under the same pressure loading. The lower stress is attributed to the material properties of the composite aramid fibre and HDPE where the elastic modulus is lower compared to glass epoxy, thus allowing more deformation at lower stresses. Furthermore, although the interlocking mechanism of the woven configuration is expected to improve the overall strength of the pipe, the simulation suggests that the numerous contacts between the hoop and tensile tapes have caused a higher stress between the contact surfaces. This can be seen in Figure 7 where higher stress occurs between the contact surfaces compared to the free surface. The reason for this behaviour is due to the friction between these surfaces where higher normal loads result in higher friction and wearing. This was demonstrated in a study by [26], where the relation of friction and normal loads are shown in Figure 9.

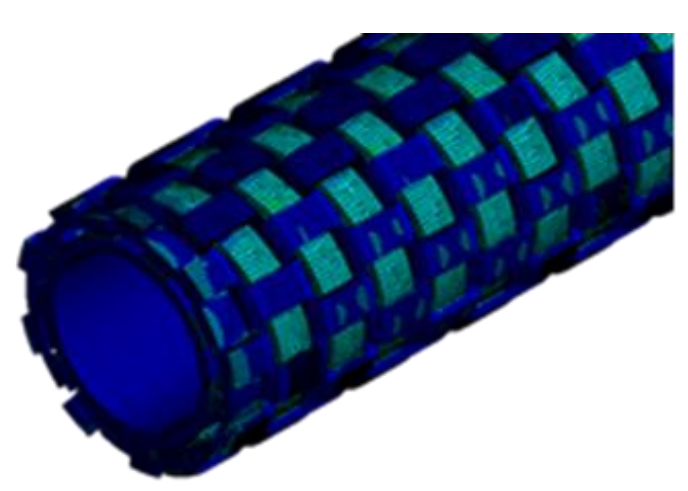

(a) woven flexible pipe

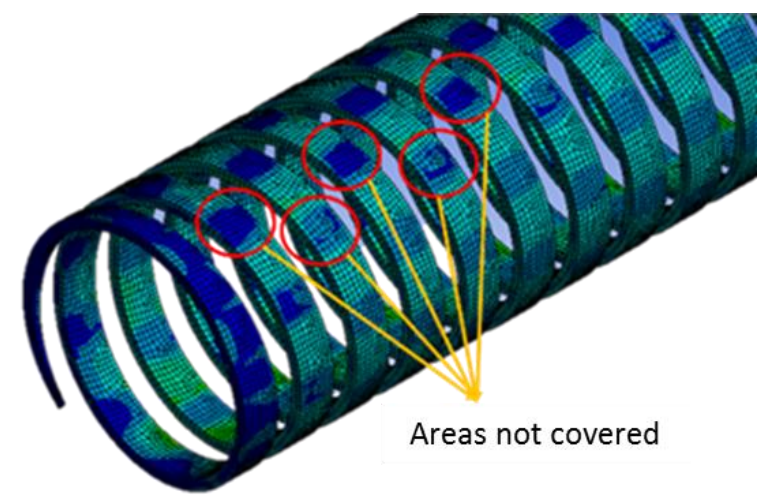

(b) hoop tape

Figure 7. Stress distribution on woven flexible pipe and hoop tape.

The optimisation of the thickness of the tapes for the woven flexible pipe depends on the required operating pressure. The optimisation of tape thickness is defined as the lowest thickness of tape required to withstand the operating pressure, which in this case is $6 \mathrm{MPa}$. Therefore, based on the loading applied, the tape thickness is optimised at a thickness of $6 \mathrm{~mm}$ as the ultimate tensile strength of the material is at $266 \mathrm{MPa}$. However, the validity of the results is still in question due to the absence of experimental data and other numerical analysis which have similar configuration and application as the woven flexible pipe to validate with (Figure 9). Therefore, at best, the result provided in this 
paper can be considered as an estimation of the performance of the woven flexible pipe for future experimental tests.

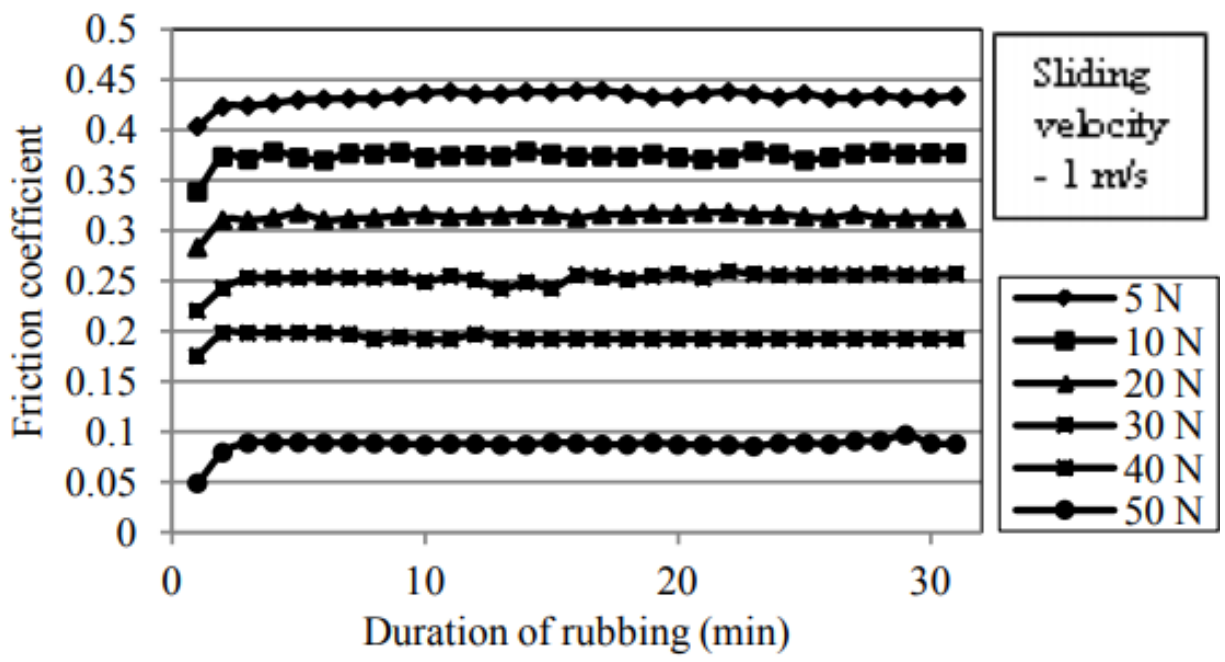

Figure 8. Stress distribution on hoop tape [27].

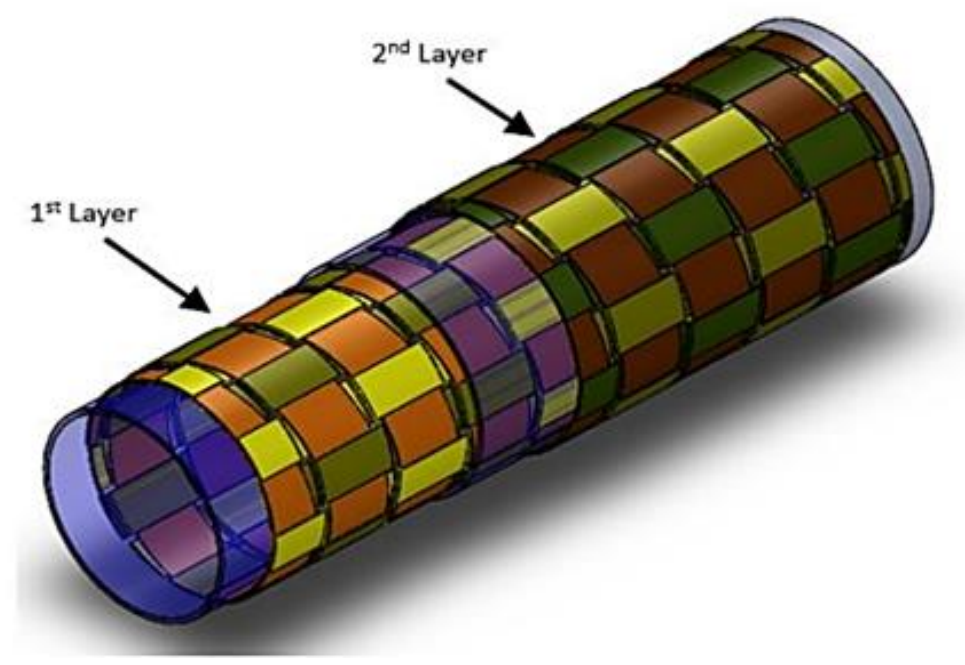

Figure 9. Multilayer woven flexible pipe.

\section{CONCLUSIONS}

A comparison has been made between the performance of the woven flexible pipe and the RTP in terms of the stress experienced from the same internal pressure loading. In terms of stress experienced, the woven flexible pipe experiences $50.8 \%$ higher stress than the RTP. However, in terms of burst strength, the RTP is able to withstand pressure up to 113 bar. On the other hand, the woven flexible pipe can withstand a pressure of $6 \mathrm{MPa}$ by using thermosetting tapes of $6 \mathrm{~mm}$ thick. Therefore, at $6 \mathrm{MPa}$, the thickness of the thermosetting tapes is optimised at $6 \mathrm{~mm}$ thickness. The numerical results however still require validation from experimental tests and thus can only serve as an estimation on the performance of the woven flexible pipe. The success of this research would deem the design of the pipe to be suitable as a corrosion resistant pipe for deepwater applications. 


\section{ACKNOWLEDGEMENTS}

This research was supported by the Technology Innovation Program (Grant No.: 10053121) funded by the Ministry of Trade, industry \& Energy (MI, Korea) and Energy Efficiency \& Resource of the Korea Institute of Energy Technology Evaluation and Planning (KETEP) grant funded by the Korea government Ministry of Knowledge Economy (Grant No.: 2014301002-1870). The authors would also like to thank for the great support of POSTECH, POSCO, and Daewoo E\&C, Republic of Korea.

\section{REFERENCES}

[1] Palmer AC, King RA. Subsea Pipeline Engineering: PennWell; 2004.

[2] Bai Y, Bai Q. Subsea Pipelines and Risers: Elsevier Science; 2005.

[3] Do AT, Lambert A. Qualification of unbonded dynamic flexible riser with carbon fibre composite armors. Offshore Technology Conference. 2012;1-18.

[4] Head WJ, Pappas JM. RPSEA program riser technologies and strategies. The Offshore technology conference. 2013:1-10.

[5] Dodds N, Jha V, Latto J, Finch D. Unbonded flexible pipe : Composite reinforcement for optimized hybrid. Offshore Technology Conference. 2015;112.

[6] Do AT, Legeay S, Pere JM, Charliac D, Roques JP, Karnikian A. New design of lightweight flexible pipe for offshore oil offloading transfer. Offshore Technology Conference; 2014.

[7] Anderson Ta, Vermilyea ME, Jha V, Dodds N, Finch D, Latto JR, et al. OTC 24160 Qualification of flexible fiber-reinforced pipe for 10 , 000-foot water depths. Offshore Technology Conference. 2013:1-9.

[8] Do AT, Bernard G, Hanonge D. Carbon Fiber armors applied to presalt flexible pipe developments. Offshore Technology Conference. 2013:1-13.

[9] Obrien P, Meldrum E, Overton C, Picksley J, Anderson K, MacLeod I. Outcomes from the sureflex joint industry project - An International initiative on flexible pipe integrity assurance. Offshore Technology Conference; 2011;1-9.

[10] Simonsen A, Janssen E, Paton C. Inspection and monitoring techniques for unbonded risers and pipelines: University of Stavanger; 2012.

[11] Muren J. Flexible pipes failure modes, inspection, testing and monitoring. PSA, Norway. 2007:1-30.

[12] Subsea. Un-bonded flexible risers - recent field experience and actions for increased robustness. Norway, 2013;1-78.

[13] Charlesworth D, D'All B, Zimmerlin C, Remita E, Langhelle N, Wang T. Operational experience of the fatigue performance of a flexible riser with a flooded annulus. Offshore Technology Conference; 2011; 1-9.

[14] Kalman M, Yu L, Seymour M, Emi J. OTC 23185- Qualification of composite armor materials for unbonded flexible pipe. Offshore Technology Conference 2012:1-15.

[15] Kalman M, Yu L, Salimi A, Liu J. OTC 23931 Qualification of flexible fiberreinforced pipe for ultra-deepwater applications. Offshore Technology Conference 2014:1-14.

[16] Deheeger A, Bernard G, Secher P, Estrier P, Félix-Henry A. High pressure flexibles pipes - knowledge and qualifications at $15 \mathrm{kpsi}, 17.5 \mathrm{kpsi}$ and $20 \mathrm{kpsi}$ Design Pressure. Offshore Technology Conference. 2014:1-16. 
[17] Gibson AG. The cost effective use of fibre reinforced composites offshore. Research Report. University of Newcastle Upon Tyne for the Health and Safety Executive. 2003;1-132.

[18] Singh BP, Singh D, Mathur RB, Dhami TL. The advantages of epoxy resin versus polyester in marine composite structures. Nanoscale Research Letters. 2008.

[19] Kaw AK. Mechanics of Composite Materials: Taylor \& Francis; 1997.

[20] Garcez MR, Filho S. A comparative study of reinforced concrete beams strengthened with glass, carbon and Aramid fibers. 2005:2005-.

[21] Bryant M. Nonmetallic unbonded flexible pipes for deep water. Society of Petroleum Engineers - 2nd International Oil Conference and Exhibition in Mexico 2007. 2007:104-8.

[22] Arbey JP, Delebecque L, Sa S, Toussaint M, Petermann N, Astrium E. Novel composite pipe-in-pipe solution for ultra deep water field developments. 2009:114.

[23] Meniconi LCM, Loureiro Jr WC, Costa dos Santos Jr F, Cunha Dias Henriques C. Strategy Concerning Composite Flowlines, Risers and Pipework in Offshore Applications. The Offshore Technology Conference. 2013.

[24] Kalman M, Yu L, Durr C. OTC 25092-MS Qualification of Unbonded Flexible Pipe to API and DNV Standards. 2014:5-8.

[25] Reutov YA. Stress-strain analysis of multilayer polymer pipes under thermal effects. 2004:833-5.

[26] SoluForce. SoluForce Classic: M480/M570 (GT).

[27] Sarkar P, Modak N, Sahoo P. Effect of Normal Load and Velocity on Continuous Sliding Friction and Wear Behavior of Woven Glass Fiber Reinforced Epoxy Composite. Materials Today: Proceedings. 2017;4:3082-92. 